Mini Review

\title{
Air pollution and respiratory health
}

\section{Raj Kumar*}

Director, Vallabhbhai Patel Chest Institute, University of Delhi, Delhi, India
As per report of WHO [1] (World Health Organization), air pollution (ambient/outdoor and household/indoor air pollution) kills an estimated seven million people worldwide every year largely as a result of increased mortality from stroke, heart disease, chronic obstructive pulmonary disease, lung cancer and acute respiratory infections. Data of WHO shows that 9 out of 10 people breathe air containing high levels of pollutants. World Health Organization is working with countries to monitor air pollution and improve air quality. From smog hanging over cities to smoke inside the home, air pollution poses a major threat to health and climate. More than $80 \%$ of people living in urban areas and around $91 \%$ of the world's population live in places where air quality levels exceed WHO limits, with developing and under-developed countries suffering from the highest exposures, both indoors and outdoors [1]. While outdoor air pollution comes from the motor vehicles, burning of fossil fuels and other industrialization activities, indoor air pollution is the result of tobacco smoke and burning fuel for cooking \& heating. Furniture and construction materials also emit such pollutants. Both outdoor and indoor air pollution are harmful to the human health

\section{Outdoor air pollution}

Air pollution is a mixture of the hazardous materials from both human-made and natural sources. Vehicular emissions, fuel oils and natural gas to heat homes, by-products of manufacturing and power generation units the primary sources of human-made air pollution. Nature releases hazardous substances into the air, such as smoke from wildfires, which are often caused by humen; ash and gases from volcanic eruptions; and gases decomposing organic matter in soils. Traffic-Related Air Pollution (TRAP), from motor vehicle emissions, is the most vulnerable and recognizable form of air pollution. It contains: ground-level ozone, various forms of carbon, nitrogen oxides, sulfur oxides, volatile organic compounds, polycyclic aromatic hydrocarbons, and fine particulate matter. Ozone, an atmospheric gas, is often called smog when at ground level. Noxious gases, which include carbon dioxide, carbon monoxide, nitrogen oxides (NOx), and sulfur oxides (Sox).

\author{
More Information \\ *Address for Correspondence: Kumar R \\ Director, Vallabhbhai Patel Chest Institute, \\ University of Delhi, Delhi, India, \\ Email: rajkumarvpci@gmail.com \\ Submitted: 05 August 2020 \\ Approved: 31 August 2020 \\ Published: 01 September 2020 \\ How to cite this article: Kumar R.Air pollution \\ and respiratory health. J Adv Pediatr Child \\ Health. 2020; 3: 032-037. \\ DOI: 10.29328/journal.japch.1001015 \\ Copyright: @ 2020 Kumar R. This is an open \\ access article distributed under the Creative \\ Commons Attribution License, which permits \\ unrestricted use, distribution, and reproduction \\ in any medium, provided the original work is \\ properly cited. \\ A) Check for updates \\ (8) OPEN ACCESS
}

Outdoor air is often referred to as ambient air. The common sources of outdoor air pollution are emissions caused by combustion processes from motor vehicles, solid fuel burning and industries. Other pollution sources include smoke from bushfires, windblown dust, and biogenic emissions from vegetation (pollen and mould spores). The most common air pollutants of ambient air include: Particulate matter (PM10 and PM2.5), Ozone $\left(\mathrm{O}_{3}\right)$, Nitrogen dioxide $\left(\mathrm{NO}_{2}\right)$, Carbon monoxide (CO), Sulphur dioxide $\left(\mathrm{SO}_{2}\right)$. As per WHO report, 4.2 million Deaths every year as a result of exposure to ambient (outdoor air pollution) and worldwide it contributes to $7.6 \%$ of all deaths in 2016. There are vulnerable group of people who are exposed to outdoor air pollution are affected more.

A study was carried out on auto rickshaw drivers of Delhi to determine the respiratory morbidity due to air pollution. The auto rickshaw drivers are directly exposed to the air pollutants for hours. It was concluded that auto rickshaw drivers have a high respiratory morbidity due to exposure to pollution. They had significantly more symptoms of cough, phlegm production, breathlessness and nasal symptoms. Their problem increases when they were in more polluted areas. The respiratory morbidity was directly proportional to the duration of their working hours [2]. A study of respiratory symptoms and lung functions of welders was performed at ten different sites in Delhi.This study has documented high presence of symptoms of chronic bronchitis, other work related symptoms and airway obstruction in welders. Longer the duration of exposure more are the chances of developing chronic bronchitis was observed [3]. The prevalence of 
asthma and wheeze were found among petrol pump workers of Delhi in the study which are similar to the prevalence of asthma and wheeze in the general population and prevalence of asthma had significant relationship highly with duration of stay in Delhi [4].

\section{Indoor air pollution}

Around 3 billion people cook using polluting open fires or simple stoves fuelled by kerosene, biomass (wood, animal dung and crop waste) and coal. Indoor/Household air pollution is one of the leading causes of disease and premature death in the developing world. Exposure to smoke from cooking fires causes 3.8 million premature deaths each year, mostly in developing and under-developed countries. Close to half of deaths due to pneumonia among children under 5 years of age are caused by particulate matter (soot) inhaled from household air pollution [1]. Household air pollution accounts for $7.7 \%$ of global [5] mortality. Nearly all deaths are in developing and under-developing countries where household air pollution is a leading cause of deaths from non-communicable disease. Common household pollutants are: Burning fuels produces a variety of health-developed pollutants including particulate matter, methane, CO, PAH and VOCs. Radon, Lead, Asbestos, VOCs and moisture build-up moulds and biological particles i.e. Dust mites, Fungi, mold, airborne bacteria, animal \& dander. Particulate matter is a pollutant of special concern. Smaller-diameter particles (PM2.5 or smaller) are generally more dangerous. The second-hand tobacco smoke and certain outdoor pollutants are known risk factors for acute respiratory infections, Indoor air pollution from biomass fuel is one of the major contributors to the global burden of disease [5].

\section{Why indoor air pollution is important}

There is a popular saying 'Home is where the heart is' [5]. Homes convey images of peace and security, protection and shelter. We spend $80 \%$ - $90 \%$ of our lives indoors. According to the Environmental Protection Agency (EPA), the average American spends $93 \%$ of their life in indoors. $87 \%$ of their life is in indoors (home, office, schools, college, and all indoor working places), then another $6 \%$ of their life in automobiles. That's only $7 \%$ of your entire life in outdoors. The people are not much aware about indoor air pollution. In one of study, it was found that $85 \%$ of the people were not aware about the indoor air pollution. It is important that people should be made aware about it.

The person's occupation is important and accordingly occupational related diseases should be treated. According to Kumar, et al. [6] in 1997, occupational asthma is a respiratory disorder characterized by intermittent and reversible obstruction of the airways and caused by inhalation of substances which are manufactured or directly used by workers at the work site. Incidences varies from 5\% - 15\%. A number of occupational exposures (e.g. nickel, asbestos, chromium, arsenic, etc.) place. individuals on increased risk for lung tumors.
In 2005, Kumar, et al. [7] in his review paper suggested that the main indoor air pollutants which are highly responsible for respiratory morbidity and mortality are: particulate matter, sulphur dioxide, nitrogen dioxide, carbon monoxide, benzene, ammonia, chloroform, formaldehyde, benzopyrene, hydrocarbons, asbestos fibers and bio-pollutants. Sources of these pollutants are: combustion by-products, environmental tobacco smoke, carpets, paints, building construction materials, transportation, incinerators, industrial exhaust and almost every manufacturing process.

These indoor air pollutants can lead to serious public health problems, including asthma, chronic bronchitis, irritation of lungs, pneumonia, decreased resistance to respiratory infection, chronic obstructive pulmonary disease (COPD), chronic cough, phlegm production, allergy, headache, fatigue, lung cancer and premature death [7].

Is outdoor air pollution source of contributions to indoor air pollution

One of the sources of the indoor air pollution is the outdoor pollution, meaning, if there is increase in the outdoor air pollution, there is increase in indoor air pollution. Kumar, et al. $[8,9]$ conclude that indoor SPM level and rhinitis and asthma in children were correlated to each other and both were higher in industrial areas. In industrial area, the indoor air pollution increases there by outdoor air pollution. Hence industries play a vital role in rhinitis in children and concentration of indoor Suspended particulate matter (SPM) in developing countries like India [8,9]. Kumar suggest that both indoor and outdoor particulate exposure may be important risk factors in the development of respiratory illness in children in which indoor air pollution in industrial areas may be a major risk factor [10]. A study was undertaken in Shahdara and Shahzadabagh which are industrial areas of Delhi, to determine mineralogical and chemical compositions of indoor suspended particulate matter (SPM) that's correlate with the health of children especially respiratory allergy [Asthma, Rhinitis and upper respiratory tract infection (URTI)] [11].

Urban air pollution is an environmental concern of many cities throughout the world and now recognized as an important health problem, both nationally and worldwide. An appraisal of indoor air quality is the most important aspect in the understanding of the impact of urban air nitrogen dioxide, carbon monoxide, carbon dioxide, ozone, volatile organic compounds are especially pulmonary disease, cough, shortness of breath, wheezing, and lung cancer, skin cancer, irritation of eyes. Particulate matter is associated with more frequent respiratory illness because airborne particulates easily reach the deepest recesses of lungs and damage. Air pollutants in urban areas having several sources such as combustion of fossil fuels, power plants, automobile exhaust, incinerators, industrial processes, and natural sources such as sea spray, volcanic eruption, pollen grains and particles of soil $[12,13]$. 
Mineral and chemical composition of Indoor air pollution and respiratory morbidity

In industrial area of Delhi, high concentration level of indoor SPM with presence of trace elements including chromium, cobalt, lead, copper, nickel, and zinc may cause the respiratory diseases including asthma, rhinitis and upper respiratory tract infection in children [14]. Another study in industrial area of Delhi revealed that high concentration level of particulate matter containing quartz, carbonate, mica, and several major and trace elements including $\mathrm{Si}, \mathrm{Cr}$, $\mathrm{Ni}, \mathrm{Pb}, \mathrm{Zi}$ and $\mathrm{Cu}$ an important factor for causing increased asthma among children [15]. Industries play valuable role for increases the concentration of indoor suspended particulate matter and occurrence of asthma in children in developing countries $[16,17]$. The high values for mean level of indoor SPM was associated with environmental factors in industrial areas of Delhi. Quartz mica contents were high in indoor SPM where children having asthma, rhinitis and upper respiratory ailments $[18,19]$.

Use of the Biomass and its use place and time of maximum indoor air pollution

Indoor air pollution from biomass fuel combustion results in an increased level of PM2.5 in indoor air, which may be responsible for increased respiratory illness in children [20-22]. The place of the kitchen, ventilation, use of the exhaust is very important factor for indoor air pollution and the respiratory morbidity. In a study it was found [23] indoor air concentrations associated with biomass smoke were fourfold greater in households of closed verandah kitchen than separate kitchen due to poorly ventilated condition and high exposure to particulates (PM1, PM2.5, and PM10) and volatile organic compounds. The study demonstrated, significantly high particulate matter (PM2.5), in households for not using a separate room for cooking with biomass fuel are the main respiratory disease causing agents in children. It was also observed that PM2.5,PM10 were significantly high(maximum) during 6-8 am and 5-7 pm.This may be during this time, the maximum cooking of the food takes place in this area. It was also observed that inspite of having Liquid petroleum gas (LPG) in their houses, they prefer to cook the food on the biomass.

Not only biomass fuel, LPG also increase the concentration of indoor air pollutants and may subsequently play a significant role in the development of respiratory allergy [24].

In 2016 [25], concentration of indoor air pollutants ( 24 hrs. PM2.5 and 12-hour concentration of VOC) were found high in households in low socio economic status households as compared to households of middle/high socio economic status with PM2.5 being statistically significant. This might be due to decreased use of exhaust in kitchen and increased use of kerosene oil. The increased reporting of respiratory symptoms in low socio economic group may be attributed to higher levels on indoor air pollutants.
In Some studies Kumar [26-28] suggests that BMF play a major role to occurrence of asthma and COPD in adults (smokers \& non-smokers) in the developing countries like India where BMF is main fuel for cooking in rural areas.

Kumar, et al. [29] in 2016 concluded that Airway obstruction in children was occurred where families were using Biomass fuel (BMF) for cooking. So this study suggests that BMF play a significant role to occurrence of airway obstruction in children in the developing countries like India where BMF is main fuel for cooking in rural areas.

Tobacco use, indoor air pollution and respiratory morbidity

Kumar, et al. in 2008 monitored and estimated the level of exposure to indoor $\mathrm{SO}_{2}, \mathrm{NO}_{2}$, and SPM, as well as demographic information. Indoor $\mathrm{SO}_{2}, \mathrm{NO}_{2}$, and suspended particulate matter levels were high in houses where there was a family history of tobacco smoking. $\mathrm{SO}_{2}$ level was high and $\mathrm{NO}_{2}$ and suspended particulate matter levels were significantly high in houses where children had respiratory problems [30].

Kumar, et al. in 2014 revealed that Environmental Tobacco Smoke (ETS) and biomass cooking fuels increased the concentration of SPM with heavy metals in the indoor environment. The high concentration of indoor SPM and heavy metals may be harmful for human health and may cause different types of diseases in the family members [31]. Kumar, et al. suggests that ETS and BMF play a significant role to occurrence of asthma in children in the developing countries like India where BMF is main fuel for cooking in rural areas [32].

The available evidence of toxicity, indoor concentration and number of people exposed suggest that some indoor air pollutants, mainly produced from ETS and biomass fuel may constitute significant public health problems (asthma and rhinitis) [33] and in addition to exposure to passive smoking, the indoor SPM level has significant effect on respiratory symptom of children [13]. Rhinitis was significantly high in smokers compared to smokeless tobacco users. It is further concluded that rhinitis was more common in cigarette smokers compared to bidi smokers [24]. Prevalence of asthma, rhinitis and URTI and mean level of indoor $\mathrm{SO}_{2}, \mathrm{NO}_{2}$, and SPM were significantly higher in homes with ETS

Kumar suggest that indoor air pollution from passive smoking/or second hand smoking results in increased levels of PM2.5 and volatile organic compounds in indoor air, which may be responsible for increased level of respiratory illness in children and adults [34]. Abnormally high level of breath CO observed in passive smokers exposed to ETS may suggest that these subjects may be prone to develop the tobacco related diseases [35]. Kumar, et al. [36] concluded that Bidi is more harmful or at least equally harmful as cigarette. This hypothesis is concluded by calculating pack-year for bidi, equating one bidi with one cigarette. 
Indoor air pollution and prevelance of asthma, rhinitis and upper respiratory infection

Given below are few studies done in Delhi and nearby areas of Delhi which suggest the significance of the indoor air pollution and its correlation with the respiratory morbidity

In a study on "Effect of indoor air pollution on respiratory function of children" which was done in nine zones of Delhi namely, Ashok Vihar (residential area), I.T.O. (residential area), Janakpuri (residential area), Nizamuddin (residential area), Siri Fort (residential area), Shahdara (industrial area), Shahzada Bag (industrial area), Dallupura (Village) and Jagatpur (Village) from March 2004 to July 2008, a total of 3,456 children were examined. From there, of which $26.4 \%$ children were from lower, $27.5 \%$ from middle, and $26.0 \%$ from upper socio economic classes. Among these children, $59.2 \%$ were male and $40.8 \%$ were female, $20.1 \%$ were from urban villages. Among these, $31.2 \%$ of the children's families were using biomass fuels for cooking and $68.8 \%$ were using liquified petroleum gas. Levels of indoor $\mathrm{SO}_{2}, \mathrm{NO}_{2}$ and $\mathrm{RSPM}$ were measured. Out of 3,456 children, 7.7\% Asthma, 26.1\% rhinitis and $22.1 \%$ upper respiratory tract infection (UTRI) were diagnosed following medical histories and examinations of the children were completed [17]. It was found that, in areas where the industries were there, there were more indoor air pollution and prevalence of asthma, Rhinitis was higher. Industrialization also contributes to indoor pollutants and developments/exacerbation of asthma, rhinitis and URTI in children [37].

A population based study was done at Khanpur Village, Loni, Ghaziabad, Delhi-NCR from March 2011 to Sep. 2015. A total of 1525 individuals were examined (Males- 809; Female-716) from 210 households. The adults participate in our study were 918, in which 470 males and 448 female candidates. In children there were 607 (male-339 \& females-268) children, were enrolled, of which $46.52 \%$ children were from lower, $17.11 \%$ from middle, and $36.36 \%$ from upper socio economic classes. PFT, PEFR, 24 hour monitoring of indoor air pollutants (PM10, PM2.5 \& PM1) and VOCs were measured by using spirometer, UCB/Grimm Aerosol spectrometer \& dust monitor, and Phocheck Tiger. Among these, $78.6 \%$ of the children's families were using biomass fuels for cooking, $13.9 \%$ were using liquefied petroleum gas and $7.5 \%$ were using both BMF \& LPG. Out of 607 children, 17\% Asthma, were diagnosed following medical histories and examinations of the children were completed [23].

In another study on "Indoor air pollution asthma in children: A population based study" was done at Dujana Village, Dadri, Greater Noida, Delhi-NCR from Sep. 2015 to May 2018, a total of 5066 individuals were examined (Males- 2224; female-2842) from 871 households. The adults participate in our study were 2791 in which 996 males and
1795 female candidates. In children there were 2275 (male1228 \& females-1047) enrolled, of which $1.9 \%$ children were from lower, $97.4 \%$ from middle, and $0.7 \%$ from upper socio economic classes. Among these, $83.5 \%$ of the children's families were using biomass fuels for cooking, and $16.5 \%$ were using liquefied petroleum gas. PFT, PEFR, 24 hour monitoring of indoor air pollutants (PM10, PM2.5 \& PM1) were measured by using spirometer, Grimm Aerosol spectrometer \& dust monitor. Out of 607 children, $13.4 \%$ Asthma, 26.1\% rhinitis and $22.1 \%$ upper respiratory tract infection (UTRI) were diagnosed following medical histories and examinations of the children were completed [39].

Recently Kumar, et al. [38,39] suggest that tobacco smoking, use of kerosene oil for lighting and combustion of solid fuel for cooking results in an increased level of particulate matter and VOCs in indoor air and are the major contributing factors for allergic in the paediatric population.

\section{Dhoop, incense use and indoor air pollutants}

Kumar, et al. [40] suggested that burning of dhoop, incense sticks and mosquito coil in the indoor environment emit quiet higher respirable particulate matters, which may accumulate and increse on prolonged exposure. The households should have better ventilation in order to avoid build of the PM. Thus, residing in such a higher particulate concentration may lead to serious respiratory health concerns.

\section{Pollen and pollution}

Pollen also contributes in the atmosphere and causes allergy to the patient. A study on OPD/ED visit patients and pollens count of different types of pollen provides a preliminary data of atmospheric pollen count in North Delhi region that provides information to the allergy practitioners in order to advice avoidance of exposure to allergens [41]. In 2018, Kumar, et al. also quantified and identified the pollen grains in the atmosphere of Delhi. In this study, various pollens of different plant species were counted and identified in this short study period. The common pollens found were Juniper $s p$. ., C. sativa, Pooideae grasses (e.g. Poa sp., Lolium perenne, Dactylis glomerata), C. dactylon, Amaranthus sp., C. album, $H$. autumnale, Parthenium, and Artemisia sp. in 2 months. The relationship between pollen number and respiratory allergy episodes is known. The findings of our study have shown the dominance of pollens of various plant species in the environment of Delhi with reference to effect on respiratory diseases. This short study may be helpful for the respiratory allergic patients to protect themselves from pollens [42].

\section{Birds feathers, droppings and indoor air pollution}

There are many people keep birds at their home. The feathers and the droppings of these birds contributes to indoor are pollution and exposure to these to the human being is a health issue. Bird fancier's lung (BFL) is a type of hypersensitivity pneumonitiss occurring in response to 
avian antigens (usually inhaled proteins of bird feathers and droppings). BFL can exhibit a wide range of radiological patterns, and a high index of suspicion must be maintained, with particular attention to detailed exposure history in every case of interstitial lung disease [43].

\section{Biological pollutants}

Indoor biological pollutants are also major factors contributing to the indoor air pollution. Kumar studied the indoor biological pollutants (pets and pests), and found that about $40 \%$ of asthmatic patients are sensitized to cockroach antigen and $15 \%$ to house dust mite. They are also sensitized to different pollens also [44].

Intervention to reduce the indoor airpollution and respiratory morbidity

An intervention/follow-up (3 months, 6 months and 9 months) study [45-48] conducted, in which the change in cooking fuel (BMF) to safer fuel (LPG) was found to be one of the factors on decreasing indoor pollutants and respiratory symptoms/morbidity among asthmatic children in rural areas. So Kumar suggested that the changes in the cooking fuel is better to decrease the indoor particulate matters (PM10, PM2.1 \& PM1) that controls asthmatic symptoms and decreased morbidity. To conclude, when domestic fuel was replaced with the LPG for cooking in few houses, he found out that exacerbation was significantly reduced, which shows the Government of India initiative (UJJWALA YOJNA) helps in reduction of the diseases morbidity.

Menace of Air Pollution in $21^{\text {st }}$ Century suggest that the pollution is an undesirable change in the physical, chemical or biological characteristic of air, water and soil which may affect life or create potential hazards for any living organism [49]. It is concluded that respiratory allergies (asthma, rhinitis and URTI) in children and adults could be associated with indoor ETS and biomass fuel used for cooking from the different study areas. We should also make aware the public about indoor as well as outdoor air pollution and how to protect/or avoid these for their better respiratory health.

\section{References}

1. WHO. Air quality guidelines -Air Pollution, global update. 2018 https://www.who.int/airpollution/data/cities/en/

2. Kumar R. Effect of air pollution on respiratory system of auto rickshaw Drivers in Delhi. Ind J Occ and Env Med. 1999; 3: 171-173.

3. Kumar R. A study of respiratory symptoms and lung function of welders in Delhi. Ind J Occ and Env Medicine 2000; 4: 168 - 171.

4. Gaur SN, Kumar R, Sinha R. Prevalence of bronchial asthma in petrol pump workers of Delhi. Indian J Occupat Environ Med. 2003; 7: 13-16.

5. Kumar R. Air Pollution and Respiratory Diseases. NCCP Text Book of Respiratory Medicine (Page No. 752-755). Editor: D Behra, Published by Jaypee Brothers P. Ltd. 2011.

6. Kumar R. Occupational asthma. Respiratory Diseases and air pollution disorders. IMA Publication 1997; 78-83.
7. Kumar R, Nagar JK, Gaur SN. Indoor air pollutants and respiratory morbidity - A review. Indian J Aller Asthma Immunol. 2005; 19: 1-9.

8. Kumar R, Nagar JK, Kumar H, Kushwah AS, Meena M, et al. Effect of indoor air pollution on Rhinitis in children living in industrial and residential areas of Delhi, India. KAACI-WAO Joint Congress 2006 \& $9^{\text {th }}$ WPAS. 2006.

9. Nagar JK, Kumar R, Kulshrestha R, Kumar P, Singh A, et al. Exposure of indoor air pollution and asthma in children at Delhi, India. Souvenir of the 41st Annual Conference of The Indian College of Allergy, Asthma \& Applied Immunology (ICAAICON-2007) organized by VP Chest Institute, Delhi during. 2007; 9-12: 57.

10. Kumar R, Nagar JK, Kumar H, Kushwah AS, Meena M, et al. Association of indoor and outdoor air pollutant level with respiratory problems among children in an industrial area of Delhi, India. Arch Environ Occupat Health. 2007; 62: 75-80.

11. Nagar JK, Kumar R, Shrivastava JP. Chemico-mineralogical study on indoor suspended particulate matter in the industrial areas of Delhi and its relationship with the respiratory allergy in children. Souvenir of the 41st Annual Conference of The Indian College of Allergy, Asthma \& Applied Immunology (ICAAICON-2007) organized by VP Chest Institute, Delhi during. 2007; 53.

12. Nagar JK, Shrivastava JP, Kumar R, Chandra U, Rathi B, et al. Urban Air Pollution: a global health problem - A review. Bull Env Sci 2007; 25: 201-223.

13. Kumar R, Nagar JK, Meena M, Kushwah AS, Harsh Kumar. Impact of Domestic Suspended Particulate Matter on Respiratory Function of Children. BAQ 2004. 2004

14. Nagar JK, Kumar R, Shrivastava JP. Trace elements in indoor airborne particulate matter of Delhi and its effects on respiratory allergy among children. The $13^{\text {th }}$ Joint National Conference of the Indian Chest Society (ICS) and the National College of Chest Physicians (NCCP) NAPCON - 2011" at India Habitat Centre, New Delhi. 2011; 330.

15. Nagar JK, Kumar R, Shrivastava JP. Compositional study of domestic airborne particulate matter in industrial locations of Delhi and its relationship with asthma in children. The $13^{\text {th }}$ Joint National Conference of the Indian Chest Society (ICS) and the National College of Chest Physicians (NCCP) NAPCON - 2011" at India Habitat Centre, New Delhi. 2011; 331.

16. Kumar R, Nagar JK, Goel N, Kumar P, Kushwah A, et al. Indoor air pollution and asthma in children at Delhi, India. Ann Aller Asthma Immunol. 2013; 111: A37.

17. Kumar R, Nagar JK, Goel N, Kumar P, Alka S. et al. Indoor air pollution and asthma in children at Delhi, India. Pneumonol Alergo Pol. 2015; 83; 275-282. https://pubmed.ncbi.nlm.nih.gov/26166789/V

18. Nagar JK, Shrivastava JP, Kumar R. Airborne suspended Particulate Matter \& its impact on Human Respiratory System - Mineralogical study from Shahdara\&Shahzadabagh industrial areas in Delhi (Page no. 489-509). Geo-Resources, Editor: JP Shrivastva, Published by Scientfic Publisher India, Jodhpur. 2014.

19. Nagar JK, Akolkar AB, Kumar R. A review on airborne particulate matter and its sources, chemical composition and impact on human respiratory system. Int J Environ Sci. 2014; 5: 447-463.

20. Kumar R, Singh K, Nagar S, Rai G, Kumar M, et al. Effect of Indoor air pollution on health of children in biomass fuel-using households in rural area. Lung India. 2012; 29: 23.

21. Kumar R, Singh K, Nagar S, Rai G, Kumar M, et al. Effect of Indoor air pollution on health of children in biomass fuel-using households in rural area. The $13^{\text {th }}$ Joint National Conference of the Indian Chest Society (ICS) and the National College of Chest Physicians (NCCP) NAPCON - 2011" at India Habitat Centre, New Delhi. 2011; 283.

22. Kumar R, Goel N, Gupta N, Singh K, Nagar S, et al. Indoor Air Pollution and Respiratory Illness in Children from Rural India. Indian J Chest Dis 
Allied Sci. 2014; 56: 79-83.

Pubmed: https://pubmed.ncbi.nlm.nih.gov/25230548/

23. Kumar R, Singh K, Nagar S, Kumar M, Mehto UK, et al. Pollution levels at Cooking Place and their associaton with respiratory symptoms in women in a rural area of Delhi-NCR. Indian J Chest Dis Allied Sci. 2015; 57: 225-231.

24. Mahakud GC, Nagar JK, Tabassum, Kumar R. Tobacco Consumption and its Relation with Rhinits: A Preliminary Study. Indian J Allergy Asthma Immunol. 2007; 21: 106-107.

25. Kumar R, Singh K, Kumar M, Balasubramanian V, Gaur SN. Association of Socioeconomic Status and Indoor Air Pollution Level on Respiratory Health of Children in Rural Area of Delhi-NCRatICAAICON-2015, 49 th National Conference of Indian College of Allergy, Asthma and Applied Immunology at Saveetha Medical College, Chennai. 2016.

26. Kumar R, Singh K, Nagar JK, Kumar M, Mavi AK. Indoor air pollution and asthma in women of rural area of Delhi NCR. at $50^{\text {th }}$ ICAAICON-2016, The GoldeenJubliee National Conference of the Indian College of Allergy, Asthma \& Applied Immunology held at VP Chest Institute, Delhi. 2016

27. Kumar R, Nagar JK, Singh K, Soreng A, Nagar PK, et al. COPD in Non- Smoker Village Female Residents Exposed to Biomass Fuel. The GoldeenJubliee National Conference of the Indian College of Allergy, Asthma \& Applied Immunology held at VP Chest Institute, Delhi. 2016.

28. Singh K, Nagar JK, Mavi AK, Kumar M, Kumar R. Prevalence of COPD in Adults and Associated risks Factors in Rural Regions of Delhi NCR". $20^{\text {th }}$ Joint National Conference of the National College of Chest Physicians (NCCP) and Indian Chest Society (ICS) NAPCON - 2018 on $29^{\text {th }}$ November to $2^{\text {nd }}$ December, 2018 held at Gujarat University Convention \& Exhibition Centre Ahmadabad. 2018; 144.

29. Kumar R, Nagar JK, Singh K, Soreng A, Nagar PK, et al. Association of Biomass Fuel and Airway Obstruction in Children at Rural Village of National Capital Region of Delhi. The $18^{\text {th }}$ Joint National Conference of the National College of Chest Physicians (NCCP) and Indian Chest Society (ICS) NAPCON. 2016; 184.

30. Kumar R, Nagar JK, Kushwah AS, Raj N, Meena M, et al. Indoor air pollution and respiratory function of children in Ashok Vihar in Delhi; an exposure - response study. Asia Pacific J Public Health. 2008; 1: 36-48. Pubmed: https://pubmed.ncbi.nlm.nih.gov/19124297/

31. Nagar JK, Kumar R, JP Shrivastava. Association of Heavy Metals Composition on Particulate Matter with Environmental Tobacco Smoke and Cooking Fuels in Indoor Air of Delhi. Int J Sci Nat. 2014; 5: 547-552.

32. Kumar R, Nagar JK, Singh K, Soreng A, Nagar PK, et al. Prevalence of Asthma in Children at Rural Village of India and its Association with Environmental Tobacco Smoke and Biomass Fuel. The GoldeenJubliee National Conference of the Indian College of Allergy, Asthma \& Applied Immunology held at VP Chest Institute, Delhi.2016.

33. Kumar R. Indoor air pollution from cooking fuel and lung health Occupational and Environmental Health: A Pathological Analysis. 57-70.

34. Kumar R, Singh K, Mavi A, Kumar D, Nagar S, et al. Passive smoking and Indoor air pollutants and its effects on respiratory system. International Conference on Life Science and Bioengineering (ICLSBE-2014) at Institute of Applied Medicines and research (IAMR) (Dept. of Life Sciences), Ghaziabad. 2014; 66.
35. Kumar R, Gopal C. Mahakud, Nagar JK, SP Singh, et al. Breathe Carbon Monoxide level of non-smokers exposed to environmental tobacco smoke. Indian J Chest Dis Allied Sci. 2011; 53: 215-219.

36. Kumar R, Prakash S, Kushwah AK, Vijayan VK. Breathe carbon monoxide concentration in cigarette and bidi smokers in India. Indian J Chest Dis All Sci. 2010; 52: 19-24.

Pubmed: https://pubmed.ncbi.nlm.nih.gov/20364610/

37. Kumar R, Nagar JK, Kumar P, Kushwah AS, Meena M, et al. Impact of environmental tobacco smoke and indoor air pollution on respiratory allergy on children in Delhi. Respirology. 2008; 13: A117 S.

38. Kumar R, Singh K, Nagar JK, Kumar M, Mavi AK. Association of indoor air pollution with allergic respiratory disease in children of rural area of Delhi NCR. at $50^{\text {th }}$ ICAAICON-2016, The Goldeen Jubliee National Conference of the Indian College of Allergy, Asthma \& Applied Immunology held at VP Chest Institute, Delhi. 2016.

39. Kumar R, Singh K, Nagar JK, Kumar M, Mavi AK, et al. Association of Indoor Air Pollution with Allergic Respiratory Diseases in Paediatric Population Residing in National Capital Region. Indian J Chest Dis Allied Sci. 2019; 61: 181-197.

40. Kumar R, Gupta N, Kumar D, Mavi AK, Kumar M. Monitoring of Indoor Particulate matter during burning of Mosquito Coil, Incense Sticks and Dhoop. Indian J Allergy Asthma Immunol. 2014: 28; 68-29.

41. Kumar R, Kumar M, Robinson K, Shah P, Bisht I, et al. Atmospheric pollen count in North Delhi region. Indian J Allergy Asthma Immunol. 2015; 29: 32-39.

42. Kumar R, Kumar D, Singh K, Mavi AK, Kumar M. Identification of airborne pollens in Delhi. Indian J Allergy Asthma Immunol. 2018; 32: 28-33. ISSN 0972-6691.

43. Kumar R, Singh M. Bird fancier's lung: Clinical - radiological presentation in 15 cases. Pneumonol Alergo Pol. 2015; 83: 39-44.

44. Kumar R, Kumar M, Bisht I, Singh K. Prevalence of aeroallergens in patients of bronchial asthma and/or allergic rhinitis in India based on skin prick test sensitivity. India J Allergy asthma Immunol. 2018, 31: 45-55.

45. Kumar R, Mavi AK, Singh K, Nagar JK, Kumar M. Follow-up study of patients with Asthma due to biomass fuel combustion in rural area of Delhi-NCR. The $19^{\text {th }}$ Joint National Conference of the National College of Chest Physicians (NCCP) and Indian Chest Society (ICS) NAPCON - 2017" at Science City Kolkata.

46. Kumar R, Nagar JK, Raj N, Kumar P, Kushwah AS, et al. Impact of domestic air pollution from cooking fuel on respiratory allergies in children in India. Asian Pacific J Allergy Appl Immunol. 2008; 26: 213-222. Pubmed: https://pubmed.ncbi.nlm.nih.gov/19317340/

47. Kumar R, Nagar JK, Kumar P, Kushwah AS, Meena M, et al. Impact of environmental tobacco smoke and indoor air pollution on respiratory allergy on children in Delhi. Respirology. 2008; 13: A117 S.

48. Kumar R, Singh K, Kumar M, Balasubramanian V, Gaur SN. Association of Socioeconomic Status and Indoor Air Pollution Level on Respiratory Health of Children in Rural Area of Delhi-NCRatICAAICON-2015, 49 National Conference of Indian College of Allergy, Asthma and Applied Immunology at Saveetha Medical College, Chennai. 2016.

49. Kumar R. Menace of Air Pollution in 21st Century. Indian J Chest Dis Allied Sci. 2018; 60: 5-6. 